\title{
Characterization of Poly(D,L-Lactic Acid) by Gel Permeation Chromatography
}

\author{
J. A. P. P. VAN DIJK and J. A. M. SMIT, Gorleaus Laboratories, The State \\ University of Leiden, P.O. Box 9502, 2300 RA Leiden, The Netherlands, and \\ F. E. KOHN and J. FEIJEN, Department of Chemical Technology, Twente \\ University of Technology, P.O. Box 217,7500 AE Enschede, The \\ Netherlands
}

\section{Synopsis}

A number of samples of poly(D,L-lactic acid) (PLA) with weight-average molecular weights $\bar{M}_{w}$ in the range $15,000-350,000$ were prepared by a ring-opening polymerization. The molecular weight distributions (MWDs) of these samples were determined by gel permeation chromatography (GPC). The method involves a universal calibration of the columns on the basis of polystyrene standards and a rapid iteration algorithm leading to the establishment of the Mark-Houwink relationship. In addition, osmometry and viscometry data are presented. The effect of hydrolytic degradation on the MWD of two PLA samples was studied by GPC.

\section{INTRODUCTION}

Over the past 15 years there has been an increasing interest in the application of PLA as a biodegradable polymer in medicine and surgery, ${ }^{1}$ e.g., as biodegradable sutures, ${ }^{2}$ burn wound covering, ${ }^{3}$ sustained release system, ${ }^{4}$ or as resorbable prostheses in maxillofacial, ${ }^{5}$ orthopedic, ${ }^{6}$ and recently myringoplastic surgery. ${ }^{7}$

The preferred method for the preparation of high-molecular-weight PLA is the ring-opening polymerization of the six-membered cyclic diester D,L-lactide ( $\mathrm{mp} 126^{\circ} \mathrm{C}$ ) initiated with a suitable catalyst, e.g., tin (IV) chloride, ${ }^{8}$ stannous octoate, ${ }^{5}$ or tetraphenyltin. The polymerization can be performed in solution under mild conditions ${ }^{9}$ or, preferably, in the melt at higher temperatures. $\mathrm{Pu}$ rified D,L-lactide, derived from the racemic mixture of $\mathrm{L}(+)$ lactic acid and $\mathrm{D}(-)$ lactic acid, is the molecular 1:1 compound of both enantiomers $L(-)$ lactide and $\mathrm{D}(+)$ lactide. ${ }^{10}$ There are strong indications that the degradation behavior of biodegradable polymers is affected by both molecular weight and MWD. ${ }^{11,12}$

Hitherto, however, information on the molecular weight characterization of poly(lactic acids) is limited. Nuwayser et al. ${ }^{13}$ determined the $\bar{M}_{w}$ of four poly(lactic acids), both poly(L-lactic acid) and poly(D,L-lactic acid), by GPC and found a linear correlation when $\bar{M}_{w}$ (range 20,000-300,000) was plotted against the reduced specific viscosity $\left(0.1 \% \mathrm{w} / \mathrm{v}\right.$ in dioxane). Dittrich and Schulz ${ }^{14}$ presented the following values of the Mark-Houwink (MH) parameters for poly(L-lactic acid) in chloroform at $25^{\circ} \mathrm{C}: a=0.82, K=1.29 \times 10^{-3} \mathrm{~mL} \mathrm{~g}^{-1}$, which were also applied to copolymers of $L(-)$ lactide and D,L-lactide. ${ }^{15}$ Experimental details, however, were not given. Recently, Schindler and Harper ${ }^{16}$ have established a $\mathrm{MH}$ equation by measuring the intrinsic viscosity of partially hydrolyzed PLA samples whose number-average molecular weights $\bar{M}_{n}$ had been 
derived from carboxyl end-group determinations $\left(a=0.77, K=2.21 \times 10^{-2} \mathrm{~mL}\right.$ $\mathrm{g}^{-1}$, chloroform, $30^{\circ} \mathrm{C}$ ). In this $\mathrm{MH}$ equation

$$
[\eta]=K \Gamma(a+2) \bar{M}_{n}^{a}
$$

the gamma function of $a+2$ was introduced assuming that randomly degraded polymers will possess a most probable MWD in which $\bar{M}_{w} / \bar{M}_{n}=2$. We could not justify this assumption experimentally because homogeneous degradation of PLA samples prepared with both tetraphenyltin and stannous octoate resulted in a MWD in which $\bar{M}_{w} / \bar{M}_{n}$ turns out to be lower than 2 .

Very few systematic data on the MWD as part of the characterization of PLA have been published so far. Gilding and Reed ${ }^{17,18}$ have recently paid attention to this subject. Their work, however, has mainly been concerned with the characterization of poly (glycolic acid) and copolymers of glycolide and lactide.

This article deals with the quantitative evaluation of the MWD of a number of nonhydrolyzed and partially hydrolyzed PLA samples using GPC, viscometry, and membrane and vapor-pressure osmometry. Besides, it provides a rapid method of determining the $\mathrm{MH}$ relationship in THF by combining off-line viscosity data with elution data.

\section{PROCEDURE}

Among a variety of methods of calibrating GPC columns the universal calibration has become a well-established one. According to this principle the product of the molecular weight $M$ and the limiting viscosity number (LVN) is a universal function of the elution volume $v$ for various polymers:

$$
\mathrm{M}[\eta]=\mu(v)
$$

Equation (1) is used to determine $\mu(v)$ with narrow-MWD standards of polystyrene (polymer 1). A MH equation for PLA (polymer 2) can then be established even when the samples are polydisperse. This requires the application of an iteration process. If the $\mathrm{MH}$ equations for both polymers hold in the molecular weight range studied, eq. (1) may be written as

$$
\ln M_{2}=\frac{1}{1+a_{2}} \ln \frac{K_{1}}{K_{2}}+\frac{1+a_{1}}{1+a_{2}} \ln M_{1}
$$

where $K$ and $a$, respectively, stand for the $\mathrm{MH}$ coefficient and exponent. The constants $a_{1}$ and $K_{1}$ as well as $\ln M_{1}$ as a function of $v$ are easily obtained by classical viscometry and primary calibration using the polystyrene standards. In order to evaluate $a_{2}$ and $K_{2}$, we proceed as follows. From eq. (1) it can be derived that

$$
\ln [\eta]_{2}=\frac{a_{2}}{1+a_{2}} \ln \mu+\frac{1}{1+a_{2}} \ln K_{2}
$$

This equation enables us to estimate the values of $a_{2}$ and $K_{2}$ as a first approximation. For the different PLA samples the LVNs can be measured separately. As the corresponding elution volumes, the values at the peak of the chromatograms are taken. The right-hand side of eq. (2) can now be calculated and $\ln M_{2}$ 
is obtained as a function of $v$. Using the latter relationship and the obtained value of $a_{2}$, the viscosity-average molecular weight $\bar{M}_{v}$ is calculated according to

$$
\bar{M}_{v}=\left(\int f(v) M_{2}^{a_{2}}(v) d v\right)^{1 / a_{2}}
$$

in which $f(v)$ represents the normalized chromatogram. To improve the values of $a_{2}$ and $K_{2}$ already found the measured LVNs are correlated with the aboveobtained values of $\bar{M}_{v}$, according to a $\mathrm{MH}$ relationship, producing new values of $a_{2}$ and $K_{2}$. Again these values are inserted in eq. (2) and a second calculation loop is started, resulting in new values of $a_{2}$ and $K_{2}$. An iteration performed in this way may be stopped when constant values of $a_{2}$ and $K_{2}$ are obtained. With final values of $a_{2}$ and $K_{2}$ the correct relationship between $\ln M_{2}$ and $v$ is established, allowing the calculation of the molecular weight averages.

\section{EXPERIMENTAL}

\section{Synthesis}

The preparation of the poly(D,L-lactic acid) samples via the ring-opening polymerization in the melt was based on the procedures developed by Kulkarni et al. ${ }^{19,20}$ and Sinclair and Gynn. ${ }^{5}$ With the exception of samples HJH-16 and -23 , tetraphenyltin was used as the initiator at concentrations in the range $7 \times$ $10^{-5}-1 \times 10^{-4} \mathrm{~mol} / \mathrm{mol} \mathrm{D,L-lactide.} \mathrm{For} \mathrm{the} \mathrm{preparation} \mathrm{of} \mathrm{HJH-16} \mathrm{and}-23$ stannous octoate was used at concentrations in the range (1-2) $\times 10^{-4} \mathrm{~mol} / \mathrm{mol}$ $\mathrm{D}, \mathrm{L}$-lactide. Careful purification and drying of the $\mathrm{D}, \mathrm{L}$-lactide $\left(\mathrm{mp} 53^{\circ} \mathrm{C}\right)$ is necessary to obtain high-molecular-weight poly(D,L-lactic acid). D,L-lactide was recrystallized several times from ethyl acetate, dried in a vacuum oven at room temperature, and stored in a dessiccator. Prior to use the D,L-lactide was effectively purified by passing ice-cold dry ether through a small column of the compound. D,L-lactide (1-3 g) was placed in a polymerization tube ${ }^{21}$ which was dried at $130^{\circ} \mathrm{C}$ for $24 \mathrm{~h}$ and the appropriate amount of initiator dissolved in a small amount of dry benzene (tetraphenyltin) or dry toluene (stannous octoate) was added. The solvent was evaporated at reduced pressure and the lower part of the tube was placed in an oil bath. The D,L-lactide was sublimed onto the upper part of the tube at reduced pressure, which is considered as an essential step to remove residual water and other contaminating solvents. After the sublimation was completed the tube was sealed under vacuum. Tubes containing tetraphenyltin as the initiator were placed in an oven at $178 \pm 1^{\circ} \mathrm{C}$ for $17-24 \mathrm{~h}$, those containing stannous octoate in an oven at $130 \pm 1^{\circ} \mathrm{C}$ for $48 \mathrm{~h}$ (HJH-16) or $160 \mathrm{~h}$ (HJH-23). The resulting polymers were dissolved in acetone, precipitated in water, separated by filtration, and finally dried in vacuo at room temperature. By this procedure the polymers are not fractionated. Only minor amounts of $\mathrm{D}, \mathrm{L}$-lactide are removed. In spite of the rather similar conditions applied during the melt polymerization of PLA initiated with tetraphenyltin the obtained samples differ greatly in MWD, which is not uncommon for this type of bulk polymerizations. ${ }^{21}$ A limited number of samples were chosen for this characterization study from a large set covering the molecular weight range of 10,000-150,000.

Portions of $100 \mathrm{mg}$ of a poly(D,L-lactic acid) sample were dissolved in $5 \mathrm{~mL}$ 
acetone. To each solution $0.5 \mathrm{~mL}$ deionized water was added, yielding clear acetone-water solutions. Thereafter the solutions were kept at $60-70^{\circ} \mathrm{C}$ for different periods of time. The homogeneously degraded polymers were isolated by solvent evaporation to dryness and in situ dissolved in tetrahydrofuran (THF) for characterization by GPC.

\section{Gel Permeation Chromatography}

Measurements were performed on a Waters model 150C high-pressure GPC equipped with four $\mu$-Styragel columns with exclusion limits $10^{6}, 10^{5}, 10^{4}$, and $10^{3}, \AA$ respectively. Operating conditions were solvent THF; solute PLA and polystyrenes (standards of Pressure Chemical Company); injected volume 400 $\mu \mathrm{L}$; sample concentration $0.1 \mathrm{wt} \%$; temperature of columns $31.15^{\circ} \mathrm{C}$; flow rate $1 \mathrm{~mL} / \mathrm{min}$. The polystyrenes were injected as mixtures of three or four narrow fractions.

The degraded PLA samples were measured on a Waters model 200 GPC in which four columns $\left(4 \mathrm{ft} \times 3 / 8\right.$ in.) packed with Styragel with exclusion limits $10^{5}$, $3 \times 10^{4}, 10^{3}$, and $250 \AA$ had been installed. The operational conditions were solvent THF; temperature of columns $30^{\circ} \mathrm{C}$; injection volume $1 \mathrm{~mL}$; flow rate $1 \mathrm{~mL} / \mathrm{min}$; solute concentration $0.5 \mathrm{wt} \%$.

\section{Viscometry}

Measurements were performed in a semimicroviscometer of the CannonUbbelohde type at $31.15^{\circ} \mathrm{C}$ with THF as the solvent. For the unfractionated PLA samples and polystyrene standards the LVNs were determined by the usual extrapolation to zero concentration (concentration range $0-1.5 \mathrm{wt} \%$ ).

\section{Membrane Osmometry}

Osmotic pressures were measured as a function of PLA concentration in an automatic osmometer (Hallikainen, model 361) in which a cellulose membrane (Schleicher and Schull, type RC 51) was mounted. The measurements were carried out in toluene at $35.8^{\circ} \mathrm{C}$.

\section{Vapor-Pressure Osmometry}

For the PLA samples STPZ-1 and STPZ-3a the number-average molecular weights were obtained by using a Perkin-Elmer vapor-pressure osmometer working at $52.3^{\circ}$ with toluene as the solvent. Calibrations were performed with tristearin (TRIS, $M=891$ ), sucrose octaacetate (SOA, $M=679$ ), and polystyrenes (PSs) 10,300 and 15,000 .

\section{RESULTS AND DISCUSSION}

Using the polystyrene standards we carried out a primary calibration with $M_{1}$ and $[\eta]_{1}$ as the separation parameters. The corresponding calibration plots are shown in Figures 1 and 2. Both curves may be approximated by a polynomial of the third degree (solid lines). Moreover, numerical results are collected in 


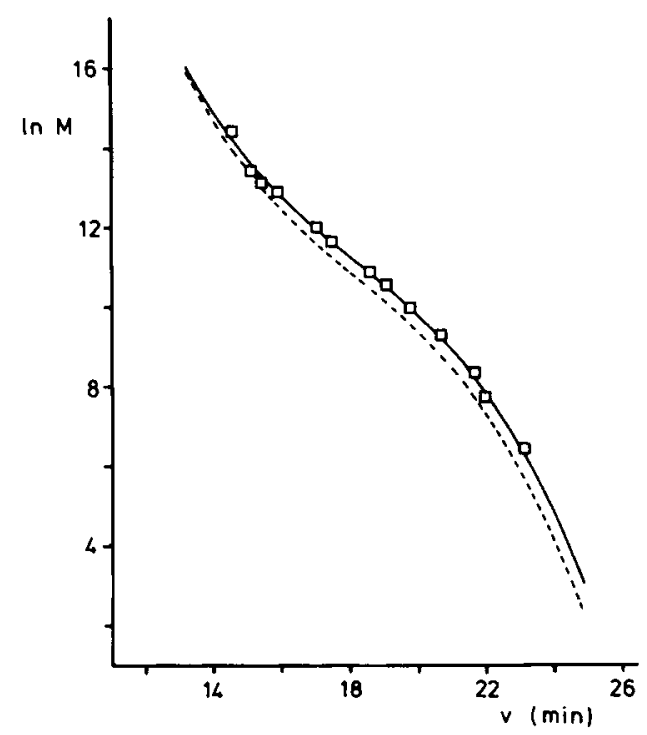

Fig. 1. Calibration curves of polystyrene (solid line) and PLA (dotted line).

Table I, showing reasonable agreement of the polynomial approximations. The MH constants obtained by the correlation of $[\eta]_{1}$ and $M_{1}$ turn out to be $a=0.717$ and $K=1.25 \times 10^{-2} \mathrm{~mL} \mathrm{~g}^{-1}$ for polystyrene in THF at $31.15^{\circ} \mathrm{C}$. The range of validity of the MH equation $\left(4,000<M<1.8 \times 10^{6}\right)$ is shown in Figure 3. These data agree with earlier data. ${ }^{22-25}$ According to eq. (1), combination of the $M_{1}$ and $[\eta]_{1}$ calibration functions results in the universal calibration function $\mu(v)$. It must be expected that $\ln \mu$ is adequately described by a polynomial of the third

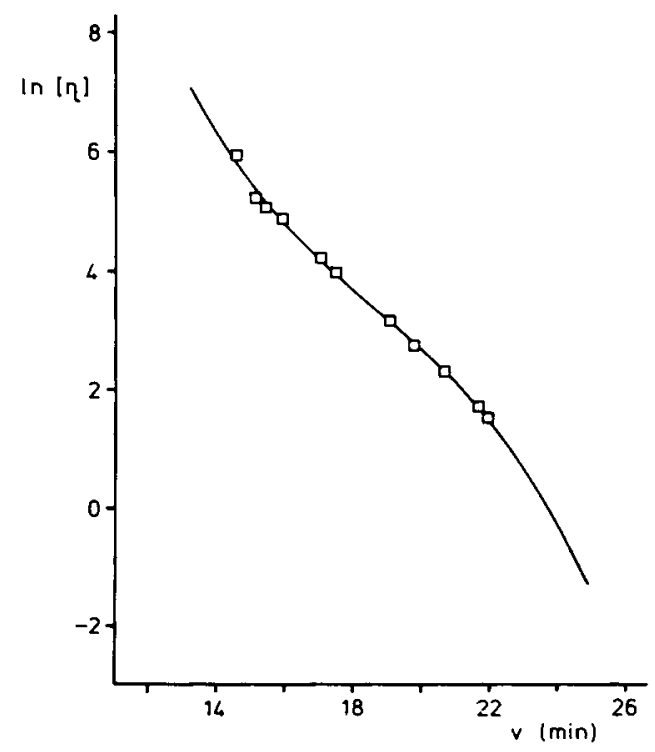

Fig. 2. Viscometric calibration data for polystyrene. 
VAN DIJK ET AL.

TABLE I

Calibration Data of Polystyrenes

\begin{tabular}{ccccc}
\hline $\begin{array}{c}v_{p} \\
(\mathrm{~min})\end{array}$ & $M \times 10^{-3}$ & $\begin{array}{c}M \times 10^{-3} \\
\text { fit }\end{array}$ & $\begin{array}{c}{[\eta]} \\
\left(\mathrm{mL} \mathrm{g}^{-1}\right)\end{array}$ & $\begin{array}{c}{[\eta]} \\
\text { fit } \\
\left(\mathrm{mL} \mathrm{g}^{-1}\right)\end{array}$ \\
\hline 23.12 & 0.6 & 0.6 & & \\
21.94 & 2.2 & 2.7 & 4.56 & 4.47 \\
21.65 & 4.0 & 3.7 & 5.46 & 5.44 \\
20.65 & 10.3 & 10.0 & 9.76 & 10.01 \\
19.75 & 20.4 & 21.1 & 15.5 & 16.2 \\
19.05 & 37.0 & 35.5 & 23.2 & 23.1 \\
18.56 & 51.0 & 50.1 & & \\
17.47 & 110 & 108 & 53.2 & 50.6 \\
17.02 & 160 & 149 & 68.3 & 64.2 \\
15.89 & 390 & 372 & 129 & 125 \\
15.40 & 498 & 586 & 157 & 172 \\
15.09 & 670 & 799 & 186 & 215 \\
14.53 & 1800 & 1479 & 378 & 331 \\
\hline
\end{tabular}

TABLE II

Iterative Approach to MH Parameters of PLA

\begin{tabular}{ccc}
\hline $\begin{array}{c}\text { Iter- } \\
\text { ation }\end{array}$ & $\boldsymbol{a}_{2}$ & $\begin{array}{c}K_{2} \times 10^{2} \\
\left(\mathrm{~mL} \mathrm{~g}^{-1}\right)\end{array}$ \\
\hline 0 & 0.707 & 2.52 \\
1 & 0.665 & 4.05 \\
2 & 0.649 & 4.88 \\
3 & 0.643 & 5.25 \\
4 & 0.641 & 5.40 \\
5 & 0.640 & 5.46 \\
6 & 0.639 & 5.49 \\
7 & 0.639 & 5.50 \\
8 & 0.639 & 5.50 \\
9 & 0.639 & 5.50 \\
10 & 0.639 & 5.50 \\
\hline
\end{tabular}

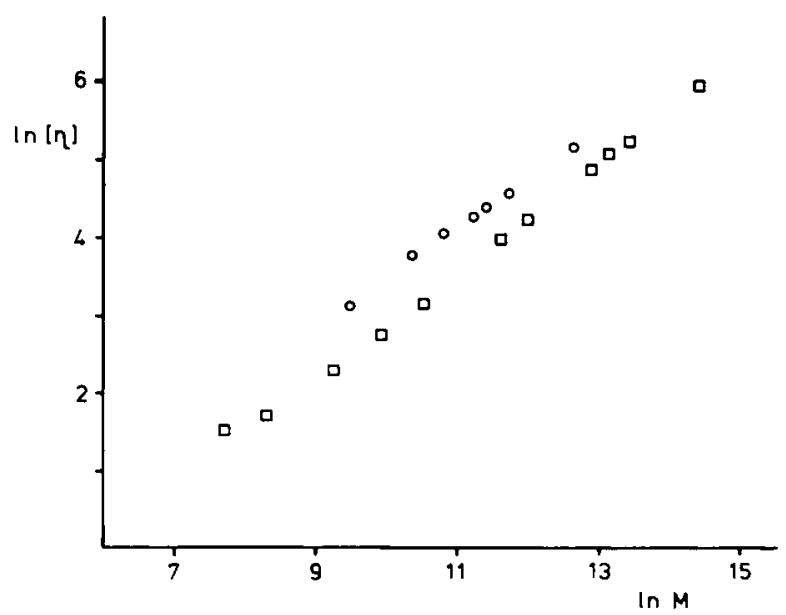

Fig. 3. MH relationship for polystyrene (ם) and PLA (O). 


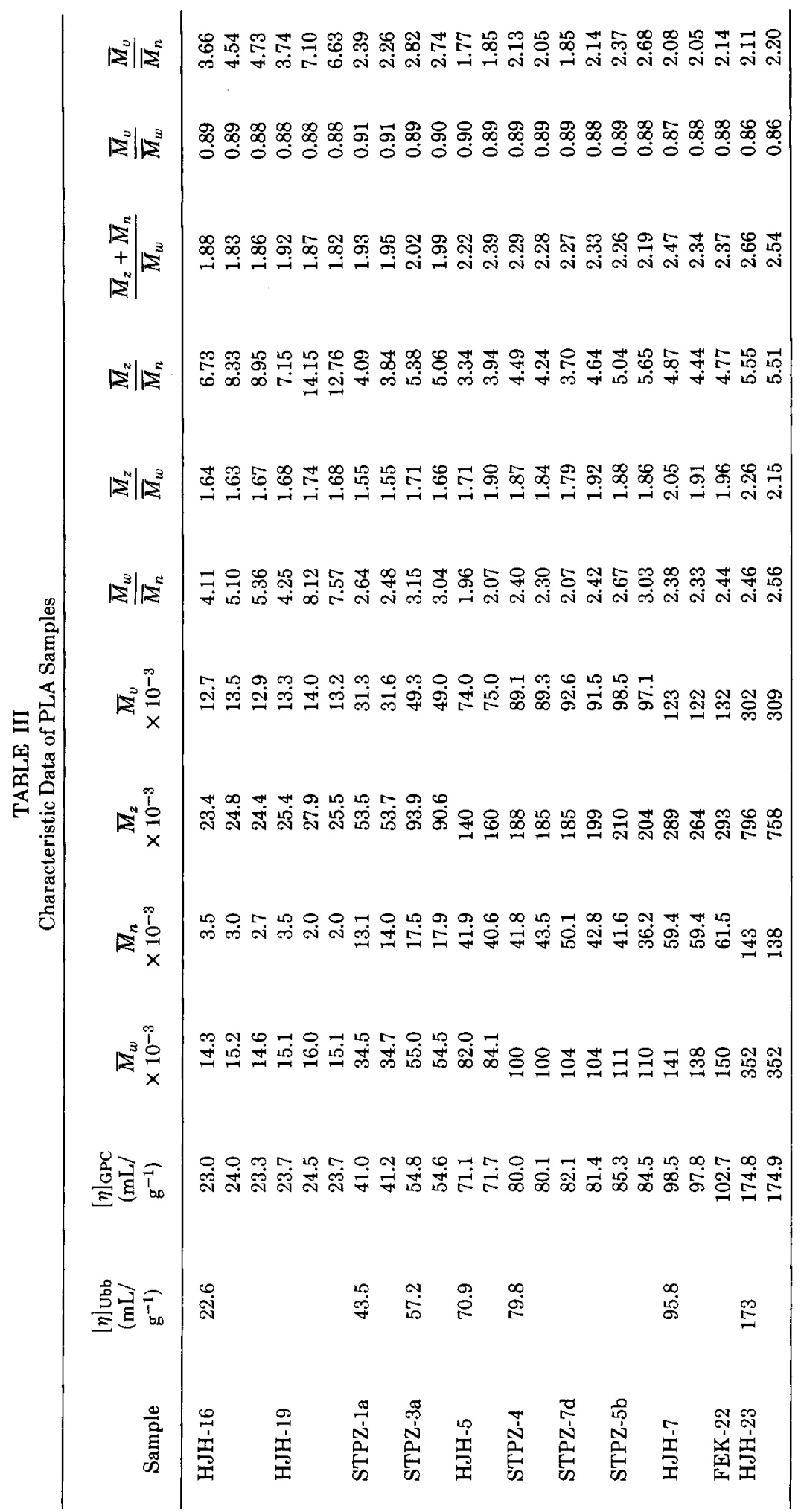


TABLE IV

Molecular Weights from Vapor-Pressure Osmometry

\begin{tabular}{lrrrr}
\hline & \multicolumn{4}{c}{ References } \\
\cline { 2 - 5 } Sample & SOA & TRIS & PS 10,300 & PS 15,000 \\
\hline SOA $(M=679)$ & & 730 & 890 & 830 \\
TRIS $(M=891)$ & 830 & & 1090 & 1130 \\
PS 10,300 & 7800 & 8400 & & 9400 \\
PS 15,000 & 11,000 & 11,800 & 14,400 & \\
PLA STPZ-1 & 6500 & 7000 & 8500 & 8900 \\
PLA STPZ-3a & 8700 & 9400 & 11,500 & 12,000 \\
\hline
\end{tabular}

TABLE V

Comparison of Molecular Weights of PLA by Vapor-Pressure Osmometry (VPO), Membrane Osmometry (MO), and GPC

\begin{tabular}{lccc}
\hline Sample & $\begin{array}{c}\bar{M}_{n} \times 10^{-3} \\
\text { (GPC) }\end{array}$ & $\begin{array}{c}M_{n} \times 10^{-3} \\
\text { (VPO) }\end{array}$ & $\begin{array}{c}\bar{M}_{n} \times 10^{-3} \\
(\mathrm{MO})\end{array}$ \\
\hline STPZ-1 & 13.5 & 8.5 & 28.2 \\
STPZ-3a & 17.7 & 11.5 & 35.1 \\
HJH-5 & 41.3 & & 45.2 \\
STPZ-7d & 46.4 & & 58.4 \\
HJH-7 & 59.4 & & 66.0 \\
FEK-22 & 61.5 & & 62.0 \\
\hline
\end{tabular}

degree in $v$. The values of the $\ln \mu$ function at the peak elution volumes of the PLA chromatograms are of interest because according to eq. (3) they can be correlated to the experimentally determined values of $\ln [\eta]_{2}$. From a linear regression of seven pairs of points it is found that $a_{2}=0.707$ and $K_{2}=2.52 \times 10^{-2}$ $\mathrm{mL} \mathrm{g}^{-1}$. With these values the iterative calculation described in the former

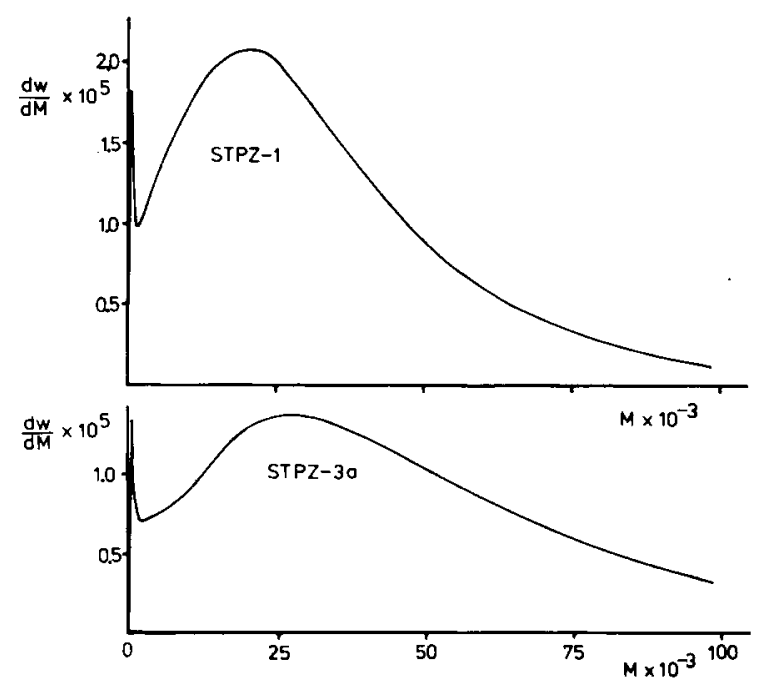

Fig. 4. MWDs of two typical PLA samples showing the presence of material with low molecular weight. 


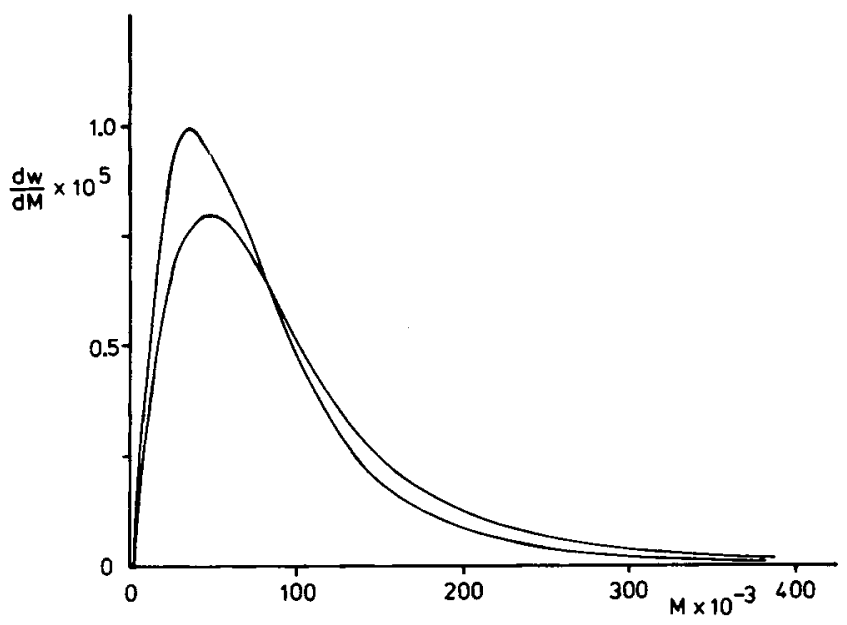

Fig. 5. MWDs of two PLA samples in the range of high molecular weights.

section is started. Table II shows the values of the MH constants found in the subsequent iterations. The rapid convergence of the iterative calculation leads to constant values of $a_{2}$ and $K_{2}$. For further operation they have been fixed at $a_{2}=0.639$ and $K_{2}=5.49 \times 10^{-2} \mathrm{~mL} \mathrm{~g}^{-1}$. Using these values and the measured LVNs a MH plot has been constructed in Figure 3.

Once the constants $a_{1}, a_{2}, K_{1}$, and $K_{2}$ are known, eq. (2) establishes the relationship between $M_{2}$ and $M_{1}$ or $M_{2}$ and $v$. As a result the two calibration curves shown in Figure 1 are almost parallel because the factor $\left(1+a_{1}\right) /\left(1+a_{2}\right)$ deviates not more than $5 \%$ from unity. The fact that the two curves do not coincide reveals the necessity of the universal calibration.

On the basis of the calibration function $M_{2}(v)$ the polydispersity of the PLA samples has been determined in terms of the molecular weight averages (Table III). The ratios found in Table III indicate that the MWDs roughly approach the Schulz-Zimm distribution $\left[\left(\bar{M}_{n}+\bar{M}_{z}\right) / \bar{M}_{w}=2\right.$ and $\left.1<\bar{M}_{z} / \bar{M}_{w}<2\right]$. Samples HJH-5 and STPZ-7 tend to have the most probable distribution $\left\{\bar{M}_{w} / \bar{M}_{n}=2 ; \bar{M}_{z} / \bar{M}_{n}=3 ; \bar{M}_{v} / \bar{M}_{n}=\left[\Gamma\left(a_{2}+2\right)\right]^{1 / a_{2}}=1.83\right\}$. The consistency of the algorithm appears from the agreement between $[\eta]_{\text {Ubb }}$ and $[\eta]_{\text {GPC }}$, the latter calculated using eq. (4) and the relationship $[\eta]_{\mathrm{GPC}}=K_{2} \bar{M}_{v}^{a 2}$. The $\bar{M}_{n}$ results in Table III were verified by osmotic measurements. Data originating from vapor-pressure osmometry have been collected in Table IV. It is observed that only if the molecular weights of sample and standard are close together are re-

TABLE VI

Influence of Axial Dispersion on Calculated Polydispersity Ratio of Polystyrenes

\begin{tabular}{ccc}
\hline & \multicolumn{3}{c}{} & $\bar{M}_{w} / \bar{M}_{n}$ & Real \\
\cline { 2 - 3 }$M \times 10^{-3}$ & Observed & $<1.10$ \\
4.0 & 1.14 & $<1.06$ \\
37.0 & 1.05 & $<1.10$ \\
\hline 390.0 & 1.12 & $<$ \\
\hline
\end{tabular}


liable values found. Hence for the PLA samples the values 8,500/8,900 and $11,500 / 12,000$ are most appropriate. Table V shows the GPC data in comparison with the results obtained by osmometry. The observed discrepancies in the low-molecular-weight range are easily explained. Samples STPZ-1 and STPZ-3a contain relatively high amounts of low-molecular-weight material (see Fig. 4), which were disregarded in the evaluation of the chromatograms. Consequently, $\bar{M}_{n}$ values obtained from vapor-pressure osmometry turn out to be smaller than the corresponding GPC values. Compared to the latter, membrane osmometry yields too high values of $\bar{M}_{n}$ if solute permeation through the membrane occurs. This effect, reflected by a decline of the experimental osmotic pressure in the course of time, was indeed observed, being more pronounced for the samples possessing the lower $\bar{M}_{n}$ values. For the high-molecular-weight samples the agreement between GPC and osmotic data is fairly good (see Table V). Although a very slight solute permeation was observed the MWDs did not indicate large amounts of low-molecular-weight substances (Fig. 5).

In the above discussion the effect of zonal dispersion was completely disregarded. As Table VI shows, only small discrepancies were found between the real and the observed values of the polydispersity of three polystyrene standards. The effect of hydrolysis of PLA and the MWD was studied using the samples HJH-7 and HJH-23. The molecular weight averages of the partially hydrolyzed samples are summarized in Table VII. The chromatograms were measured in this case with a GPC operation at low pressure. According to a method described earlier, ${ }^{26}$ the obtained normalized chromatograms were transformed into integral distribution curves which were combined with the known MWDs. Comparison of the corresponding values in Tables III and VII shows that no serious errors are introduced by the transformation. For the interpretation of the results in Table VII it is interesting to consider the assumption of Schindler and Harper ${ }^{16}$ that the hydrolysis of PLA must proceed as a random chain scission process and necessarily must lead to the most probable MWD. This assumption, which in-

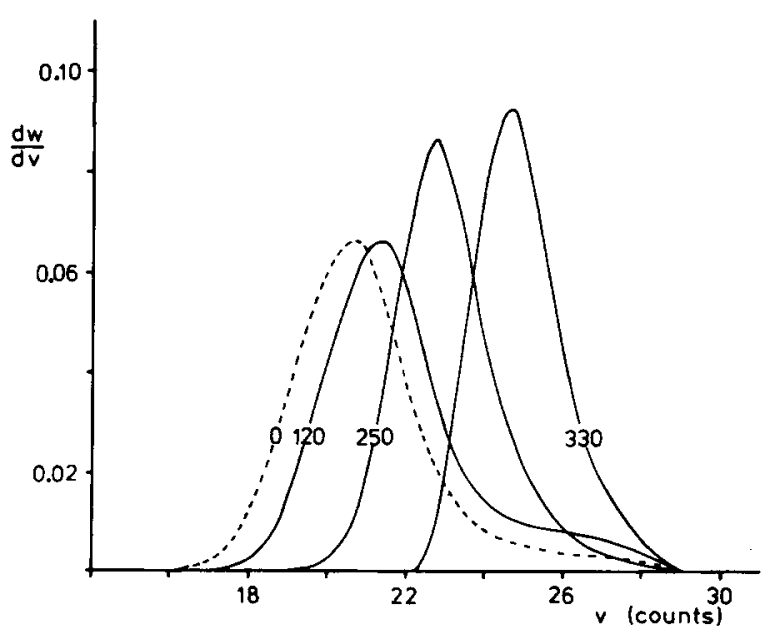

Fig. 6. Degradation behavior of PLA; normalized chromatograms are given as a function of time $(0,120,210,330 \mathrm{~h})$. 
deed is very plausible a priori, is not confirmed by our experiments. Instead it is striking that after hydrolysis MWDs are obtained with $\bar{M}_{w} / \bar{M}_{n}<2$ and in the case of sample HJH-23 rather near unity. This evolution to a narrow MWD, which emerges clearly from Figure 6, warrants further investigation.

The authors would like to thank Waters Associates (Etten-Leur, The Netherlands) for placing the GPC apparatus at their disposal, Mr. H. Heuvink and Mr. S. Tuinhout for their contributions to the synthetic part of this investigation, Dr. J. W. A. van den Berg and Mr. G. van de Ridder for helpful discussions, and Mrs. T. van Gils for typing the manuscript.

\section{References}

1. R. L. Kronenthal, in Polymers in Medicine and Surgery, R. L. Kronenthal, Z. Oser, and E. Martin, Eds., Plenum, New York, 1973, pp. 119-137.

2. J. W. Hodge, Jr., U.S. Nat. Tech. Inform. Serv. AD Report No. 742719 (1971).

3. J. B. Gregory, A. D. Schwope, D. L. Wise, U.S. Nat. Tech. Inform. Serv., AD Report No. 759381 (1971).

4. L. C. Anderson, D. L. Wise, and J. F. Howes, Contraception, 13, 375 (1976).

5. R. G. Sinclair and G. M. Gynn, U.S. Nat. Tech. Inform. Serv. AD Report No. 748411 (1972).

6. R. K. Kulkarni, E. G. Moore, A. F. Hegyeli, and F. Leonard, J. Biomed. Mater. Res., 5, 169 (1971).

7. L. Feenstra, B. W. C. van der Ven, F. E. Kohn, and J. Feijen, Int. J. Artif. Organs, 3, 354 (1980).

8. E. Lillie and R. C. Schulz, Makromol. Chem., 176, 1901 (1975).

9. R. C. Schulz, in Proceedings, IUPAC International Symposium Macromolecular Chemistry, Budapest, 1969, pp. 185-212.

10. G. J. van Hummel, S. Harkema, F. E. Kohn, and J. Feyen, Acta Crystallogr., B38, 1679 (1982).

11. W. R. Vezin and A. T. Florence, J. Biomed. Mater. Res., 14, 93 (1980).

12. C. G. Pitt, D. Christensen, R. Jeffcoat, G. L. Kimmel, A. Schindler, M. E. Wall, and R. A. Zweidinger, in Proceedings, Drug Delivery Systems, H. L. Gabelnick, Ed., DHEW Publ. No. (NIH)77-1238, U.S. Department of Health, Education and Welfare, Washington, DC, 1976, pp. 141-192.

13. E. S. Nuwayser, D. L. Williams, P. M. Meier, T. C. Wu, S. F. Merchant, and J. H. Kerrigan, in Proceedings, Drug Delivery Systems, H. L. Gabelnick, Ed., DHEW Publ. No. (NIH)77-1238, U.S. Department of Health, Education and Welfare, Washington, DC, 1976, p. 193.

14. W. Dittrich and R. C. Schulz, Makromol. Chem., 15, 109 (1971).

15. E. W. Fisher, H. J. Sterzel, and G. Wegner, Kolloid Z. Z. Polym., 251, 980 (1973).

16. A. Schindler and D. Harper, J. Polym. Sci. Polym. Chem. Ed., 17, 2593 (1979).

17. D. K. Gilding and A. M. Reed, Polymer, 20, 1459 (1979).

18. D. K. Gilding, A. M. Reed, and I. N. Askill, Polymer, 22, 505 (1981).

19. R. K. Kulkarni, K. C. Pani, C. Neuman, and F. Leonard, U.S. Nat. Tech. Inform. Serv. AD Report No. 636716 (1966).

20. R. K. Kulkarni, K. C. Pani, C. Neuman, and F. Leonard, Arch. Surg., 93, 839 (1966).

21. R. D. Lundberg, J. V. Koleske, and K. B. Wischmann, J. Polym. Sci. A-1, 7, 2915 (1969).

22. H. Benoit, Z. Grubisic, P. Rempp, D. Decker, and J. G. Zilliox, J. Chim. Phys. Tome, 63, 1507 (1966).

23. G. V. Schulz and H. Baumann, Makromol. Chem., 114, 122 (1968).

24. Th. Provder and E. M. Rosen, Sep. Sci., 5, 437 (1970).

25. D. J. Goedhard and A. Opschoor, J. Polym. Sci. A-2, 8, 1227 (1970).

26. J. A. P. P. van Dijk, W. C. M. Henkens, and J. A. M. Smit, J. Polym. Sci. Polym. Phys. Ed., 14, 1485 (1976).

Received January 6, 1982

Accepted July 28, 1982 